\title{
La fe del pueblo del Antiguo Testamento frente al sufrimiento (II) El problema de Job y la Sabiduría
}

\author{
Rafael de Sivatte, \\ Centro de Reflexión Teológica, \\ San Salvador.
}

\section{El libro de Job'}

\subsection{El significado universal del libro}

Desde un punto de vista histórico hay que tener en cuenta que el libro de Job es posiblemente una obra que fue escrita a lo largo de varios siglos. Lo que queda claro es que el escrito, tal como ahora lo poseemos, debe ser lefdo a partir del cúmulo de males y sufrimientos, que le sobrevinieron al pueblo a lo largo de la historia, el exilio y el postexilio, la experiencia del mal y del sufrimiento. Desde esa experiencia se hicieron cada más agudas las preguntas sobre el mal y el sufrimiento y también la pregunta sobre Dios y su relación con los que padecen el mal y el sufrimiento. Veamos en este contexto qué nos dice el libro de Job.

Para comenzar, el planteamiento del libro de Job es tal que tiene un significado universal, es decir, no se fija sólo en lo que pueda ocurrir a una persona o a un pueblo determinado, sino en que el problema del mal y del sufrimiento alcanza a todos los pueblos y personas del universo. Esto se nota en varias cosas: habla del Dios universal y no de Yahveh, el Dios de Israel; presenta a Job como un patriarca oriental y no como un personaje típicamente judro; los hechos tienen

1. En el análisis del libro de Job he tenido muy presente el libro de Gustavo Gutiérrez Hablar de Dios desde el sufrimiento del inocente. Una reflexión sobre el libro de Job, Lima, 1986. Puede verse tambien Gerhard von Rad, "El libro de Job", Sabiduría de Israel, Madrid, 1985, pp. 261-286; Jean Lévêque, Job. El libro y su mensaje, Estella, 1987; Luis Alonso Sehökel y Jose Luis Sicre Díaz, Job. Comentario teologico y literario, Madrid, 1983; Rafael de Sivalte Alguero, "El libro de Job", La sabiduría de Israel. ¿conformismo o liberación?, San Salvador, 1992, pp. 29-51; Robert Michaud, La literatura sapiencial. Proverbios y Job, Estella, 1985. 
lugar en Edom, no en Israel ni en Judá; los amigos que dialogan con Job son sabios de Arabia y no del pueblo de Dios. También hay que tener en cuenta que el planteamiento tiene algo de caricaturesco, pues no hay duda de que el Job que se presenta en el libro es bueno y es justo; tiene algo de religioso, pues lo que está en juego es la justicia de Dios; no es simplista, ni conformista, sino valiente y radical, es decir, quiere llegar al fondo del asunto.

El libro, tal y como ha llegado hasta nosotros, ofrece una gran unidad a pesar de que, en su origen, parece que hubo varios pequeños escritos de tiempos y respuestas muy diferentes.

\subsection{Análisis de las diversas partes del libro}

Veamos por partes el libro, comenzando por las más antiguas y subrayando el mensaje que quieren transmitir.

\section{a) Cuento primitivo en prosa $(1,1-5.13-20.22 ; 42,11-15)$}

Esta parte es aproximadamente del año 1000 a. C. Nos explica que Job era bueno, rico y feliz - aunque le comienzan a sobrevenir desgracias-, los suyos lo acompañan y consuelan. Gracias a Dios vuelve a ser feliz.

Job... era un hombre..., temeroso de Dios y apartado del mal... Era el más rico de toda la gente de Oriente. Sus hijos tenían por costumbre juntarse para comer... Una vez acabados estos días de fiesta, Job los llamaba para purificarlos..., pues pensaba que a lo mejor habían pecado maldiciendo a Dios en su interior. Siempre hacía lo mismo... Un día en que sus hijos e hijas comían y bebían en casa de su hermano mayor, llegó un mensajero donde Job diciendo: "Estaban los bueyes arando y las burras pastando al lado, y de pronto han cardo sobre ellos los sabeos y se los han llevado, después de haber matado a los siervos a filo de espada". Todavía estaba éste hablando, cuando llegó otro con el siguiente mensaje: "Tus hijos e hijas estaban comiendo y bebiendo en casa del hermano mayor; de repente, un viento huracanado del otro lado del desierto ha embestido contra los cuatro ángulos de la casa, que se ha derrumbado sobre los jóvenes y han muerto". Se levantó Job, rasgó su manto y se rapó la cabeza; después cayó en tierra en actitud humillada... A pesar de todo, Job no pecó ni imputó nada indigno a Dios... Fueron a verle todos sus hermanos y hermanas, junto con sus conocidos, y comieron en su casa... le consolaron por la desgracia que le había infligido Dios. Cada uno le regaló una moneda de plata y un anillo de oro. Dios bendijo ahora a Job más que al principio... Tuvo también siete hijos y tres hijas... Su padre las hizo herederas junto con sus hermanos.

Con este cuento primitivo se quiere decir que el mal y el sufrimiento provienen de un modo natural, que para poder asumir y superar la situación difícil es importante el ambiente de apoyo familiar y que Dios vuelve siempre a enviar 
bendiciones sobre el justo. En último término, Dios lo rehabilita. No aparece. por tanto, ninguna problematización del sufrimiento.

b) Dramatización posterior, también en prosa (1, 6-12.21; 2, 1-10; 42, 16-

17; rambién los cambios de Yahveh en lugar de Elohim en 1, $21-22$ y en 42, II- (2)

Esta dramatización es del año 550 a. C., aproximadamente. Como en un buen drama, aparecen varios personajes: Dios, el acusador, la mujer de Job, más Job, con sus hijos, hijas y sirvientes, que ya estaban presentes, en el cuento primitivo.

El acusador pide permiso a Dios dos veces para poner a prueba la autenticidad de la relación de Job con Dios, y Dios se lo concede. Caen sobre Job toda clase de desgracias y aparentes maldiciones de Dios, y Job acepta la situación como había aceptado antes las bendiciones de Dios.

Los hijos de Dios fueron a presentarse ante Yahvé, apareció también entre ellos el Satán. Dijo entonces Yahvé al Satán: ... “ ¿Te has fijado en mi siervo Job?... es un hombre... temeroso de Dios y apartado del mal". Respondió el Satán a Yahvé: “... ¿No ves que lo has rodeado de protección? ... Trata de poner la mano en sus posesiones; te apuesto a que te maldice a la cara". Contestó Yahvé al Satán: "De acuerdo... pero no le pongas la mano encima". Y el Satán salió de la presencia de Yahvé... Y Job [ante todos los males que le cayeron] dijo: "Desnudo salí del seno matemo y desnudo volveré a él. Yahvé me lo ha dado y Yahvé me lo ha quitado. Bendito sea el nombre de Yahvé"... Dijo Yahvé al Satán: “... iTe has fijado en mi siervo Job? ... A pesar de todo, persevera en su integridad"... Contestó el Satán a Yahvé: “...dáñalo en los huesos y en la carne; te apuesto a que te maldice a la cara". Respondió Yahvé al Satán: "Lo dejo en tus manos, pero respeta su vida". El Satán salió de la presencia de Yahvé. E hirió a Job con úlceras malignas ... Job se sentó en el polvo... Su mujer le dijo... : “ ¿Aún persistes en tu integridad? Maldice a Dios y muerete". Job le respondió: "Hablas como una tonta. ¡Resulta que estamos dispuestos a recibir de Dios lo bueno y no lo estamos para recibir lo malo!". A pesar de todo, Job no pecó con sus labios... Job... conoció a sus hijos, nietos y biznietos. Job murió anciano tras una larga vida.

Esta dramatización posterior al cuento primitivo expresa que desde la experiencia de una fuerte relación con Dios, cualquier nueva realidad es ocasión para aceptar a Dios. En otras palabras, sí es posible una relación auténtica con Dios, que no esté guiada por intereses personales, sino fundamentada en la experiencia y la confianza en él.

En esta dramatización, por lo tanto, como en el cuento primitivo, aparece la aceptación del sufrimiento y el encuentro con Dios, en ese sufrimiento. Pero todo ello ocurre de una manera que, por así decirlo, no es normal en el ser 
humano: sin búsqueda de explicaciones, sin crítica, sin rebelión... Y esta aceptación simplista del sufrimiento no ayuda, de hecho, ni prepara a seguir por el camino del sufrimiento, aprendiendo a descubrir a Dios en él.

A eso responde la mayorfa de la obra en verso, que ha quedado en medio del texto. Ahí aparece el inconformismo, la rebeldía, el realismo y la radicalidad, con lo cual se presenta el camino pedagógico para aceptar el sufrimiento de forma auténtica, de modo que éste pueda ser revelación de Dios.

c) Unidad en verso $(3-27 ; 29-31 ; 38,1-42,6)$

Esta parte del libro es del año 475 a. C., aproximadamente, en pleno postexilio. En ella se dice que Job se rebela contra lo que le está ocurriendo, que los amigos "consoladores" quieren evitar que llegue a maldecir a Dios, sin que se deje convencer por ellos, que pide a Dios que le responda, que Dios le responde de una manera desconcertante y que, en último término, él acepta con toda madurez el sufrimiento y el mal como lugar en el cual también Dios se hace presente.

Su intención es mostrar el camino necesario para que el ser humano pueda asumir, de modo humano, el sufrimiento como realidad reveladora de Dios. Ese camino comienza con el monólogo del capítulo 3, del que cito a continuación algunos fragmentos.

Job... maldijo el dia de su nacimiento... "Muera el día en que nací.. Que ese día se vuelva tinieblas... que la oscuridad se apodere de él... Que se ofusquen las estrellas de su aurora... por no haberme cenado las puertas del vientre... ¿Por qué no morl antes de nacer?... Ahora reposaría en paz... ¿Por qué dio... vida [Dios]... a los hombres carentes de futuro porque Dios les ha cerrado el paso? En vez de pan, me encuentro con sollozos... Me sucede lo que más temra... Carezco de paz... todo es sobresalto.

Como vemos, Job comienza maldiciendo el gran don de la vida y desea morir, ya que no murió al nacer. ¿Tendrá razón el acusador, el Satán, que aseguraba que Job maldecira a Dios, cuando éste le retirase sus bendiciones materiales y cuando el mal y el sufrimiento empezasen a venir sobre él? Parece que si, pero eso es sólo el comienzo del drama.

Nos encontramos a continuación con el diálogo de Job y sus tres amigos. Tres veces toman la palabra cada uno de los amigos, y Job tiene que ir respondiendo. Los amigos lo condenan para salvar la justicia de Dios, pero Job insiste en que lo importante para él es saber si Dios lo condena.

Veamos, en primer lugar, algunos fragmentos de los textos, donde aparecen las afirmaciones de los amigos en que, para defender que Dios es justo, insisten una y otra vez en que sólo los injustos padecen el mal y sufren. Con esto están diciendo que, si Job sufre, es porque es injusto. Son muchos los textos donde 
aparecen estos argumentos de los amigos. He aquí algunos fragmentos de Job 4, I - 5,$27 ; 8,1-22 ; 11,1-20 ; 15,1-35 ; 18,5-21 ; 20,1-29$.

Recuerda: ¿que inocente ha perecido?... quienes cultivan maldad y siembran desgracia, las cosechan. Ante el aliento de Dios perecen... He tenido una revelación... of una voz: “¿Puede un mortal ser justo ante Dios...? Si ni siquiera confra... en sus ángeles... ¿qué decir de los que viven entre adobes?... mueren desprovistos de sabiduría"... Yo que tú acudirfa a Dios... El hace prodigios... pone... a los afligidos en lugar seguro... Amuina los planes de los astutos para que no prosperen sus intrigas... El arranca... al pobre de la mano opresora... ¡Dichosa la persona a quien Dios corrige!... porque hiere y pone la venda.. Gustarás de la paz de tu tienda... Conocerás numerosos descendientes... Bajarás a la tumba bien maduro... Esto lo tenemos comprobado...

¿Puede Dios torcer el derecho...? Si tus hijos pecaron contra él, ya los puso en poder de su delito. Pero si buscas pronto a Dios... si eres... recto... te devolverá tus legittimos bienes... Pregunta... a pasadas generaciones... De ayer somos nosotros... Pero ellos te instruirán... “ ¿Brota el papiro fuera de la marisma?... antes que cualquier hierba se agosta. Así es el fin de quien de Dios se olvida... Pero Dios no rechaza al honrado, ni echa una mano al malvado. Aún puede llenar tu boca de risas... la tienda de los malvados desaparecerá.

Has dicho: "Mi conducta es pura..." ¡Pero ojalá Dios te hablase... sabrias entonces que Dios te pide cuentas de tus faltas... ¿Pretendes descubrir la hondura de Dios...? Pues bien conoce a la gente falsa... Si... extiendes tus manos hacia él, si rechazas la maldad que hay en tus manos... alzarás la frente limpia, te podrán acosar, pero no temerás... vivirás confiado en la esperanza... muchos buscarán tus favores. Pero los ojos del malvado se consumen... su esperanza es el último suspiro.

Tu boca te condena, que no yo... ¿Has asistido al consejo divino y has asimilado la sabiduría? ¿Qué sabes tú que no sepamos?... ¡Cómo te domina la pasión... cuando arremetes airado contra Dios... ¿Qué es el hombre para creerse puro?... Si ni siquiera confía en sus santos... iqué decir... del hombre que se ahoga en maldad!... te contare lo que he visto... la tradición recibida: son contados los años reservados para el opresor... No se enriquecera ni durará su fortuna... pues acabará en vanidad... Es estéril la ralea del impío... Quien concibe maldad pare desgracia...

La luz del malvado se apaga... lo pierden sus propios proyectos... la trampa le espera en el camino... El mal devora su piel... Su recuerdo se borra en el país, se queda sin nombre... Así acaba... la casa del que a Dios desconoce. ¿No sabes tú que desde siempre... el júbilo del malvado es breve?... Aunque... su cabeza alcance las nubes, desaparece para siempre... El ojo que lo veŕa ya no lo verá... Indemnizarán sus hijos a los pobres... Le sabía dulce la 
maldad... pero ese manjar se corrompe en sus entrañas... vomitará las riquezas devoradas, pues Dios se las saca del vientre... Devolverá sus ganancias sin probarlas... Por... robar casas en vez de construirlas... sus tesoros no lo salvarán... Su propia abundancia lo acosará... Dios le enviará el ardor de su cólera, como lluvia de flechas en su carne... Un diluvio arruina su casa, los torrentes del día de la ira. Esta es la suerte que Dios depara al malvado.

En estos textos aparece claramente que los argumentos de los amigos se basan en que a los buenos todo les va bien, a pesar de que dicen que no es posible que haya alguien que sea bueno ante Dios y que Dios no confía, ni siquiera en sus propios ángeles. Su conclusión, por tanto, es clara. El sufrimiento es castigo justo de Dios, por un pecado personal o familiar, consciente o inconsciente. Incluso llegan a afirmar que Dios olvida la parte mayor de dicho pecado y, en consecuencia, está castigando con mucha misericordia. En definitiva, si Job sufre es porque es injusto y pecador y no porque Dios sea injusto. Lo que está haciendo Dios es castigarlo, iy no con toda la dureza que merecía!

A continuación, Job, basándose en la experiencia que ha tenido y tiene de relación con Dios, rechaza esa visión, que le presentan los amigos. Mal favor le hacen a Dios defendiendolo de una manera que, en realidad, lo empequeñece.

He aqur algunos fragmentos de los textos en los que Job muestra su resistencia a aceptar la visión de Dios, que los amigos le presentan $(7,16-21 ; 10,1-22$; $13,3-28 ; 16,1-6.19-21 ; 19,13-17 \mathrm{a} ; 24,1-12)$ :

[¡Dios mío!], déjame en paz... ¿Qué es el hombre... para que pongas en él tu interés, para que... a cada instante lo pongas a prueba? ¿Dejarás alguna vez de mirarme?, ¿me darás tiempo a tragar saliva? Si he pecado, ien qué te afecta?... ¿Por qué convertirme en blanco?... ¿Por qué no... pasas por alto mi culpa, si pronto yaceré en tierra y no estaré aunque me busques?

...Voy a hablar henchido de amargura. Diré a Dios: “... explícame por qué me atacas. ¿ Te parece bien... despreciar la obra de tus manos...? ¿ $i$ Es tu existencia la de un mortal, son tus años los de un hombre, para que... investigues mi pecado, aunque sabes que no soy culpable...? Tus manos me formaron... ¿y ahora, en arrebato, me destruyes? Recuerda que me has hecho de barro... Me revestiste de carne y piel... Me concediste el don de la vida... Pero... seguro que estabas pendiente... de no disculpar mis faltas: si era culpable, jay de mí!; si inocente, no levantaría cabeza... Con la furia de un león me das caza... ¿Por qué me sacaste del vientre? Habría muerto sin que nadie lo advirtiese... Aléjate de mí, déjame gozar un poco antes de que marche, y ya no vuelva".

...Yo quiero... encararme a Dios, pues... sólo son médicos de apariencia... atiendan a la defensa de mis labios. ¿Van a usar la mentira en defensa de Dios? ... ¿Serán parciales con Dios? ... ¿No sería mejor que los sondeara? ... 
¡Qué duda cabe que los castigaría por su... parcialidad! ¿No los asusta su majestad... Máximas de ceniza son sus denuncias... Voy a hablar yo. Me ocurra lo que me ocurra... pondré mi vida en juego... aunque quiera matarme, lo esperaré, pues pienso defenderme a su cara; con eso me daría por salvado, pues el impío no comparece ante él... ya he dispuesto mi defensa, yo sé que soy inocente... "Hazme ver mis delitos y errores. ¿Por qué... me tienes por enemigo? ¿Por qué asustas a una hoja que vuela?... Me haces pagar faltas juveniles... vigilas todos mis pasos".

"Sólo son consoladores agobiantes...". También yo hablaría como ustedes, si es que estuvieran en mi lugar... Pero hablo y no se calma mi dolor, me callo y no se aleja de mí... Pero tengo en el cielo mi testigo, mi defensor... ante quien vierto mis lágrimas. Que él juzgue entre el hombre y Dios...

Mis hermanos se alejan de mí... Me abandonan vecinos y parientes, se olvidan de mí mis invitados... Llamo a mi esclavo y no responde, aunque yo en persona le suplique. Mi aliento repugna a mi esposa... También los niños me muestran desprecio... Todos mis íntimos me aborrecen... Mis huesos se pegan a la carne y a la piel... ¡Piedad, piedad, amigos!, que la mano de Dios me ha herido. ¿Por qué me persiguen como Dios?...

Los malvados desplazan linderos, roban... se llevan... toman en prenda el buey de la viuda. Apartan del camino a los pobres... Arrancan del pecho al huérfano, toman en prenda la comida del pobre. Gimen los moribundos en la ciudad, los heridos piden socorro, pero Dios no escucha su oración.

Como se ve, los argumentos de Job se fundamentan en su experiencia de relación con Dios. Afirma que sí se considera pecador, como cualquier otro. Ve que, según la teoría de sus amigos, todos los seres humanos deberían ser castigados. Pero esta misma imagen de un Dios castigador no concuerda con su experiencia de fe. Acusa, en consecuencia, a sus amigos de que han defendido una imagen falsa de Dios, que han querido alienar, separar a Job de la auténtica experiencia de fe y que no lo han acompañado de verdad.

En este tenso diálogo, Job y los amigos van viviendo lo que Gustavo Gutiérrez llama un cierto desplazamiento o desinstalación. Job cae en la cuenta que sufre, en medio de la gran masa de quienes sufren; no es el único. Por otra parte, descubre que el sufrimiento es provocado y agudizado por la conducta de quienes son injustos y que, de este modo, triunfan y van a más. Capta, finalmente, que bondad-maldad, justicia-injusticia son mesurables y verificables por la acción a favor o en contra del prójimo.

Todo esto obliga a Job a vivir su dolor sin cerrarse al dolor de las demás personas. Obliga también a los amigos a defender a Dios, afirmando que la felicidad de los injustos, es decir, de los que han maltratado a los inocentes, es pasajera y afimando, en consecuencia, que Dios está castigando a Job por actos 
concretos de injusticia contra los prójimos. Es lo que, de un modo u otro, aparece en el siguiente texto: $22,6-11.21-30$ :

Exigías sin razón prendas a tus hermanos, despojabas de su ropa al desnudo; no dabas de beber al sediento, privabas de pan al hambriento; como poderoso... despedías a las viudas de vacío, destrozabas los brazos de los huérfanos. Por eso... la luz se oscurece y no ves, te engullen aguas caudalosas... Reconciliate con él y haz las paces, y te será devuelta tu dicha. Si vuelves a Shaddai con humildad... a Dios alzarás u rostro; le rezarás, te escuchará... tendrás éxito en tu empresa, brillará en tus sendas la luz. El humilla la empresa arrogante... pone a salvo al hombre inocente...

Se ha llegado así a un impasse, ya que entre los muchos que sufren es seguro que hay al menos un inocente, que no ha cometido injusticia contra los prójimos. ¿Cómo explicar entonces su sufrimiento? Además, si Job demuestra que no ha hecho nada, en contra de los demás, como lo acusan sus amigos, se tendrá que aceptar que es inocente y, en consecuencia, volverá a surgir la pregunta de por qué sufre.

Job profundiza, a continuación, y cae en la cuenta de que es justo, precisamente, por su atención y solidaridad con los pobres, una atención y una solidaridad desinteresadas y gratuitas, que le salen de lo más interno de su ser. Y esto es lo que pone ante Dios mismo (cfr. 29 - 31), del modo siguiente:

a. En el pasado era justo y todo le iba bien (Job 29).

b. En el presente todo le va mal (Job 30).

c. En realidad, él no ha cambiado de conducta, sino que sigue siendo justo como antes (Job 31).

Veamos una selección de estos tres capitulos.

¡Si pudiera recuperar... los días en que Dios me protegía... cuando aún Shaddai me acompañaba y todos mis hijos me rodeaban, cuando bañaba mis pies en leche y la roca destilaba arroyos de aceite... Me escuchaban todos expectantes, en silencio para oír mi consejo... me esperaban como a lluvia temprana... Si yo les sonreía, apenas lo creían... Me ponfa al frente marcando el camino, como rey... quien me vela, se ponía de mi parte, pues yo libraba al pobre en apuros, al huérfano privado de ayuda. El descarriado me bendecía, a las viudas devolvía la alegría. La justicia era la ropa que vestía... Yo era ojos para el ciego, yo era pies para el cojo, yo era padre de los pobres, abogado del desconocido. Rompra los colmillos del inicuo, le arrancaba la presa de los dientes. Me decía: “...alargaré mis días... mi arco se afianzará en mi mano" (29).

Ahora, en cambio, se ríen de mí personas más jóvenes que yo... La fuerza de sus brazos no servía, carentes como estaban de vigor, agotados del hambre y 
la penuria... moraban en escarpas de barrancos, en grutas y grietas de la roca... ;Gente villana y sin apellido, gente expulsada del pais! Ahora, en cambio, me hacen coplas y hasta me sacan refranes... escupen a mi paso sin reparo. Dios... me humilla, y ellos se desenfrenan al verme... trabajan en $\mathrm{mi}$ ruina.. Y ahora... me tocan días de aflicción. De noche el mal... me agarra con fuerza... me arroja en el barro, parezco polvo y ceniza... Te pido auxilio y no respondes... Te has vuelto cruel conmigo... Sé que me devuelves a la muerte ... ¿Acaso no tendŕ la mano al indigente cuando angustiado pedía justicia?... ¿no he mostrado piedad por el pobre? Esperaba... la luz, llegó la oscuridad... Me he vuelto hermano de chacales... Tengo... los huesos consumidos por la fiebre. Mi arpa es instrumento para duelo, mi flauta acompaña a plañideros (30).

Mas, ¿qué suerte depara Dios desde arriba?... ¿No reserva desastre al injusto...? ¿No... cuenta todos mis pasos? ¿Me he... encaminado hacia el fraude? Que me pese en balanza sin trucar y Dios conocerá mi integridad. Si aparté mis pies del camino dejándome llevar por mi capricho... ique otro coma mi siembra, que me arranquen mis retoños! Si cedŕ a la atracción de otra mujer y en la puerta de mi amigo aceché, ique muela para otro mi esposa, que un extraño se acueste con ella!... Si denegué el derecho a mi siervo y a mi sierva en sus litigios conmigo... Cuando Dios... pase cuentas, ¿qué responderé?... ¿No... nos formó iguales en el seno? Si mi tierra protesta contra mí....que en vez de espigas dé espinas... Si me cerré a la necesidad del debil y dejé morir de llanto a la viuda, si comí solo mi ración sin compartirla con el huérfano... si vi sin ropa a un... indigente, si no me bendijeron sus cuerpos, calientes con la lana de mis corderos; si alcé mi mano contra el huérfano... ique se me salga de la espalda el hombro... Pues temo el castigo de Dios... No puse mi confianza en el oro... no puse mi gozo en mi inmensa riqueza... Viendo lucir el sol... la luna, no me dejé seducir secretamente mandándoles un beso con la mano... No me alegré del mal del enemigo... Nunca dormía en la calle el forastero, pues abría mis puertas al viajero. No oculté a los hombres mi delito... por miedo al desprecio de los míos...jOjalá que alguien me escuchara! ¡He dicho mi última palabra! A Shaddai le toca responder (31).

Tras este largo monólogo, los amigos ya nada pueden decir. Job espera que Dios le responda, a pesar de que los amigos siempre le han dicho que Dios no le responderá, pues no quiere trato alguno con él, o que, si le responde, lo hará desde la tempestad para destruirlo.

Job espera la respuesta, habiendo aprendido que muchos inocentes sufren y que su sufrimiento no es, por tanto, castigo; que ser humano es acompañarlos y suavizar su dolor, a pesar del propio dolor; que ser humano y justo, por tanto, es ser desinteresado, en esta relación con los que sufren, sin esperar nada de ellos; que Dios le pide que tenga esta relación con los que sufren y se vaya metiendo en la dinámica de la gratuidad para poderse relacionar gratuitamente también 
con Dios; que actuando así es justo y, por tanto, su propio dolor no puede ser interpretado, de ninguna manera, como castigo, por su injusticia.

Asf, pues, desde la experiencia humana del dolor propio y ajeno, desde el combate espiritual que ha librado, Job ha ido experimentando la confirmación de la amistad y cercanía de Dios. Ha ido creciendo su firmeza y su confianza en Dios. Este crecimiento queda muy bien plasmado en 19, 25-27, en el cual Job afirma la certeza de que vive su defensor, Dios, y de que él, aunque se haya quedado sin piel ni carne, verá a Dios con sus propios ojos. Veámoslo.

Yo sé que vive mi Defensor, que se alzará el último sobre el polvo, que después que me dejen sin piel, ya sin carne, veré a Dios. Sí, seré yo quien lo veré, mis ojos lo verán, que no un extraño.

Dios le responde, finalmente, y no defrauda su confianza. Y no sólo esto, sino que, además, le responde de algún modo a sus preguntas. Le responde desde la tormenta, desde la que sus amigos le decían que lo destruiría. Y le responde no para condenarlo, sino para comunicarse con él y para comunicarle cosas importantes, para compartir con él sus secretos más íntimos.

¿Qué le responde, en el fondo? ¿Qué le comunica? Que la grandeza de Dios no está tanto en el poder para destruir el mal y para hacer la justicia, sino en la libertad y gratuidad del amor. Sus amigos así van a quedar totalmente descalificados. Pero veamos la respuesta más en detalle, que es doble. Hay una primera respuesta ante la duda de Job de que la obra creadora tenga sentido y una segunda ante el cuestionamiento de Job sobre el gobierno justo de Dios, en la historia.

Ante el cuestionamiento que hace sobre el sentido de la obra creadora de Dios, sobre la finalidad de su creación, éste le va a responder que sus proyectos creadores nacen de la gratuidad del amor creador. Pero, ¿cómo lo hace? En un tono muy irónico, Dios pregunta a Job con la esperanza de que éste, ya que tiene tanta experiencia por los muchísimos años que ha vivido, le dé una lección sobre los grandes misterios de la naturaleza. Dios le habla de la tierra, del mar, de la mañana, de la muerte, de la luz, de las tinieblas, de la nieve, del granizo, del viento, del aguacero, de las lluvias, de las gotas de rocío, del hielo, de la escarcha del cielo, de las constelaciones, del firmamento, de las nubes, de los rayos.

En esta primera parte de su discurso, en la cual trata, sobre todo, de los grandes fenómenos de la naturaleza, Dios, en forma de preguntas, va compartiendo con Job, como con un amigo, lo más profundo de su saber y aquello que Job, solo, de ningún modo podría soñar conocer. Hay, además, un aspecto que queda claro, en esta primera parte. Me refiero a cuando Dios le pregunta a Job: "¿quién abre un canal al aguacero, un camino a las nubes tomentosas, para que rieguen tierras despobladas, zonas desérticas deshabitadas, para que sacien soledades desoladas y brote verdor en el páramo?" (38, 25-27). En este fragmento, Dios inicia el tema de la gratuidad. Es decir, que Dios no ha creado las cosas 
para que estén al servicio del ser humano o de la racionalidad; al servicio de la doctrina de la retribución, para que Dios las use para premiar o castigar. La razón de ser de muchas cosas es inexplicable. Dios las ha creado gratuitamente. No hay cosa más inútil, por ejemplo, al menos aparentemente que la lluvia en el desierto. Y en cambio, Dios hace que llueva.

En la segunda parte de este primer discurso, Dios insiste en el mundo de los vivientes y le pregunta de nuevo a Job, para que se lo explique, sobre los grandes misterios del mundo animal. Le menciona el ibis y su sabidurfa, el gallo y su inteligencia, la habilidad de los leones para hacerse con sus presas, la alimentación de los cuervos, el alumbramiento de las rebecas, el parto de las ciervas, la libertad de los onagros y los asnos salvajes, la fuerza de los búfalos, la velocidad del avestruz, la bravura del caballo, el vuelo del halcón y la majestuosidad del águila. También en esta segunda parte se inicia un tema muy significativo. Entre los misterios del mundo de los vivientes, que Dios va compartiendo con Job, le comparte uno especialmente importante: los animales, los salvajes, de los que Dios habla con mayor pasión y agrado que de los otros. Le dice que a pesar de que tengan defectos, a él le agradan, especialmente, por su libertad, porque no se dejan doblegar por el ser humano. Lo más grandioso de ellos es que son libres y que Dios se siente bien con ellos, viéndolos correr lejos de la civilización, volar por las alturas, moverse sin miedo entre los peligros. Tan grande es su libertad que hace que sean valorados, a pesar de que, en algún caso, sean estúpidos, como el avestruz, que deposita los huevos en la arena y no se percata de que cualquiera que pase los puede destruir. Veamos cómo lo formula.

¿Quién deja en libertad al... asno salvaje? Yo le di la estepa por morada... se ríe del tráfago de la ciudad, no escucha al arriero vociferar... rebusca cualquier hierba tiema. ¿Está el búfalo dispuesto a servirte?... ¿Te fiarás de él porque es fuerte?, ¿le confiaras el peso de tu trabajo?... El avestruz mueve alocado las alas...; abandona en el suelo sus huevos... sin pensar que un pie puede pisarlos o una fiera salvaje aplastarlos... Es que Dios le negó sabiduría, no le dotó de perspicacia. Pero cuando se yergue en pie se ríe del caballo y su jinete. ¿Le das al caballo su bravura?... ¿Le haces saltar como langosta...? del miedo se ríe, no teme... nadie lo sujeta al toque de trompeta... ¿Vuela el halcón porque tú le enseñas...? ¿Se cieme a tus órdenes el águila y hace su nido en la altura?" (39, 5-30).

Resumiendo. En su primera respuesta, Dios se remonta a los origenes de todo y le dice a Job que es un error pensar que ha sido creado para utilidad inmediata del hombre y como para prestar un servicio a la teoría de la retribución. Además, añade, es falso que la acción de Dios sea previsible y delimitable; esto ińa contra el mismo manifestarse Dios como YHVH (véase Ex 3) a Moisés, es decir, como el que estará en la historia e irá siendo descubierto, a medida que se vaya viviendo. Menos todavía la pueden prever los seres humanos, que han llegado 
a formar parte del universo, cuando Dios ya había ordenado las cosas (donde se nota algo de la típica ironía de Dios, tan presente en este y en otros del Antiguo Testamento).

Dios, con todo, se muestra dispuesto a explicar a Job, como a un amigo, los misterios e intimidades de la creación. Job, por su parte, debe estar dispuesto a que lo sorprenda y a reconocer que no lo sabe todo. Y lo primero que Dios le explica es que la retribución, que supone una relación interesada, no sirve para entender su acción. La clave para entender la realidad es su iniciativa libre y gratuita y de su amor. Dios le pregunta, entonces, a Job varias cosas que él no tiene capacidad de responder, si sigue con su manera utilitarista de pensar. Y no las puede responder porque se mueven en un contexto de gratuidad.

¿Cuál es este contexto de gratuidad? Que Dios se complace en la gratuidad de la propia acción, que hace seres y cosas que, aparenternente, son inútiles (por ejemplo, la lluvia en el desierto), que no está encadenado, ni forzado, en una palabra, por la retribución o por la necesidad. Dios tiene planes, pero el hombre no puede conocerlos, ni calcularlos. Además, todo y no sólo el ser humano, es obra de Dios; el ser humano, por tanto, no es el centro alrededor del cual deberfa girar todo.

El contexto, además, es de libertad. Dios crea seres libres y se complace en su libertad. No hace falta que estén al servicio de los hombres: son libres, son fuertes y son independientes. Dios, por tanto, se complace en ellos no porque sean útiles o inteligentes, sino porque son libres e independientes; a fortiori, se complace también en Job.

Así, pues, el resumen de esta primera respuesta es que la creación no debe entrar en las categorías racionales y utilitaristas del ser humano, ya que el motor de los planes de Dios es su amor libre y gratuito (esto, en el mundo de la creación y en el de la historia, en lo que es y en lo que pasa). Dios corrige, de este modo, a quienes quieren forzarlo, a quienes no quieren abandonarse confiadamente a él, a quienes no quieren aceptar lo incomprensible de su libertad y de su gratuidad. Pero Job malinterpreta la respuesta de Dios y cree que lo que quiere es hacerlo callar de una vez por todas y confundirlo. En consecuencia, Job promete, en su primera respuesta, no volver a hablar:

Hablé a la ligera, ¿qué replicaré? Mejor si me tapo la boca con la mano.

Hablé una vez, no responderé; dos veces y nada añadiré (40, 3-5).

Ante lo que ha hablado Dios, parece que Job sólo puede responder, "soy poca cosa ante Dios y por esto me voy a callar". Pero esto no es lo que Dios quiere que Job responda. No deja tranquilo a Dios, pues no es un paso para reconocer la libertad y la gratuidad de Dios, y éste quiere que Job dé este paso. Dicho de otro modo, Dios no quería hacer callar a Job, sino iniciarlo en los misterios de sus planes. Es por esta razón que Dios vuelve a dirigirse a Job. 
Ahora, Dios se centra no ya en la gratuidad de la creación, sino en el gobierno justo; con ello quiere ayudarlo a salir de su cerrazón, de sus explicaciones fáciles, de su intento de coaccionar su amor libre y gratuito, de su juzgar todo con categorías humanas. Con ironía, reta a Job -que se siente más justo que él y le quiere dar lecciones- sobre cómo se debe ser justo y acabar con el mal. Lo reta a que acabe con el mal y el sufrimiento.

Yahvé respondió a Job desde la tormenta: "Si eres valiente, cínete los lomos: te voy a preguntar y tú me instruirás... ¿Tienes un brazo como el de Dios, una voz potente como la suya? Cínete, pues, de grandeza y majestad, vístete de gloria y esplendor; da rienda suelta a tu cólera, hunde de una mirada al arrogante, humilla de una mirada al soberbio, aplasta a los malvados donde estén, entiérralos juntos en el polvo, enciérralos a una en el calabozo. Entonces te alabare" (40, 6-13).

No es que Dios se conforme con el mal y el sufrimiento. Dios quiere acabar con el mal y quiere que reine la justicia, en el mundo. Es ésta su voluntad última. De ahr que a cada noche, tiempo de la injusticia y del mal que lleva al sufrimiento, el hace que siga la mañana, tiempo de la justicia y del bien (38, 12$15 ; 24,13-17)$.

En un lugar anterior del libro de Job había quedado claro que el mundo del mal, que produce sufrimiento, es el mundo de la oscuridad y de las tinieblas. Asi, se afirmaba en 24, 13-17.

Los hay rebeldes a la luz, desconocen sus caminos, no frecuentan sus senderos. Con el alba se alza el asesino, mata pobres e indigentes. De noche ronda el ladrón, asalta casas a oscuras. El adúltero espera el crepúsculo, pensando "Nadie me ve", y después se cubre el rostro. Durante el día se ocultan, pues desconocen la luz. Tienen a las sombras por mañana, habituados al terror de la noche.

Dios le pregunta entonces a Job, en 38, 12-15, si para eliminar el mal que produce sufrimiento ha hecho alguna vez algo como lo está haciendo él cada día, para mostrar su voluntad decidida de que el mal y el sufrimiento se acaben, que el bien tenga oportunidad de luchar $e$ ir acabando con el mal y el sufrimiento. Así lo expresa.

"¿Alguna vez has mandado a la mañana... para que agarre a la tierra por los bordes y sacuda de ella a los malvados... para que niegue a los malvados su luz y quede roto el brazo sublevado?".

Dios confiesa también que no quiere, ni puede destruir con una mirada a los malvados. Por respeto a lo creado y a la libertad humana, capaz siempre de conversión, se ha autolimitado: no quiere usar su poder para destruir. Así, pues, el ser hurnano no puede eliminar el mal, por su propia naturaleza; Dios no puede, 
por su autolimitación. Esta es la gran maravilla que quiere que Job comprenda: Dios es poderoso, en su obra creadora, muestra su poder en su respeto a la libertad humana y al ritmo del mundo y de la historia. Esto es lo que to hace aparecer como debil. Pero, icómo expresa todo esto? Con la presentación que hace de Behemot y Leviatán $(40,15-41,26)$. Los presenta como dos animales de gran fuerza -parece que hace alusión al hipopótamo y al cocodrilo-, pero que han sido creados por Dios.

Sobre Behemot y Leviatán se creía que en ellos estaban simbolizadas las fuerzas del caos y del desorden, que producian mal y sufrimiento. El libro de Job, en cambio, dice que por creación están bajo el dominio de Dios, cuya decisión y voluntad es que el ser humano tome como tarea llegarlos a dominar. No es que se cierren los ojos a la realidad. Es verdad que en el mundo hay caos, hay desorden y hay mal; pero también es verdad que Dios estŕ llamando al mundo a que no sea caótico, desordenado o malo. Es el hombre quien tiene que ir realizando esto. El camino, pues, para acabar con el mal, es diferente al que nosotros nos podamos imaginar, es el del respeto a la leyes y a la libertad. La tarea, pues, le queda al ser humano. Este debe ir transformando el mal en bien, el sufrimiento en bienestar.

En resumen, en esta segunda respuesta de Dios se dice que todo está bajo su poder creador, que todo está bajo la libertad del ser humano, que este mismo hecho hace aparecer a Dios como débil, cuando ésta, en realidad, es su máxima grandeza, y es también la tarea encargada a los seres humanos, la máxima grandeza de la humanidad, su máximo poder y donde se demuestra el don del amor gratuito de Dios.

Ante esto, Job responde de otra manera. Job había aceptado su pequeñez dentro del cosmos y del misterio de la gratuidad de Dios. Ahora acepta a Dios tal como es, acepta una relación con Dios libre de todo interés. Pero, ¿cuáles son los pasos de esta aceptación? Reconoce que Dios es poderoso y que tiene proyectos que puede realizar. Manifiesta también que ha descubierto que la base de acción de Dios está en la gratuidad, en el respeto a la libertad, en el deseo de que triunfe el bien. Afirma haber descubierto, en su experiencia de dolor, al Dios auténtico, al Dios que mantiene su compromiso de estar y que está con el que sufre, llamando a que se acabe todo dolor. Por todo esto, Job acepta haberse equivocado y se arrepiente del camino iniciado de penitencias; no tiene sentido seguir haciendo penitencias para ganarse a Dios, ya que éste ha estado y está siempre al lado y con Job. Acaba aceptando que Dios lo ha seducido y que se siente muy cerca de êl (42,1-6).

Sé que eres todopoderoso: ningún proyecto te es irrealizable. Era yo el que empañaba el Consejo con razones sin sentido. Si, he hablado de grandezas que no entiendo, maravillas que me superan y que ignoro. Yo te conocía sólo de ofdas, mas ahora te han visto mis ojos. Por eso me retracto y me arrepiento del polvo y la ceniza. 
Este es el núcleo del libro de Job. Pero en último término, ¿qué ha encontrado Job? Ha encontrado al Dios auténtico, no al de la religión interesada; al Dios que no quiere el caos y la injusticia, que suponen el sufrimiento y la muerte de los inocentes; al Dios que no usa su poder, destruyendo aquello o aquellos que provocan el dolor; al Dios que cuenta con los seres humanos y su libertad para acabar con la injusticia y el dolor provocado por ella; al Dios "débil", pues quiere que se realice la justicia, pero no quiere ni puede eliminar la libertad, aunque ésta, a veces, vaya contra sus planes; al Dios que sólo pretende "seducir" al hombre para que éste luche libremente contra la injusticia; al Dios que para "seducirlo", sólo le muestra su preferencia y su estar por los pobres, no porque valgan más, sino porque han sido empobrecidos y están desprotegidos.

¿Qué le supone, en último término, a Job este encuentro? Le supone no caer en una resignación impotente ante el sufrimiento del inocente, en una religión interesada y calculadora, en una actitud que olvide el dolor de los demás, en una desesperación; le supone salir del propio mundo e ir al mundo de quienes sufren alrededor, pues Dios los quiere preferencialmente; cantar y alabar al Dios que quiere liberar al sufriente, trabajando para que dicho canto y alabanza sean posibles y tengan autenticidad; tener el coraje de lamentarse ante Dios, por el sufrimiento propio y por el ajeno, confiándose a él (véase Sal 22); hacer con la propia actitud y acción que los demás descubran y encuentren al Dios que no quiere el sufrimiento del inocente, sino que lo acompaña, en todo su camino, hasta el final.

En resumen, lo que nos está diciendo Job es, en primer lugar, que desde la realidad del sufrimiento es desde la que se "conoce" auténticamente a Dios, ya que no se trata de un Dios con quien se comercia, un Dios mágico, un Dios tapaagujeros, sino del Dios metido en nuestra historia, encarnado en ella, interpelador, suscitador de personas y grupos que la transformen. $Y$ en segundo lugar, que Dios está presente y es solidario en las situaciones de sufrimiento y de dolor de los seres humanos, y de un modo especial de los inocentes, animándolos a luchar contra el sufrimiento de los demás y contra el sufrimiento propio.

\section{El libro de la Sabiduría y el sufrimiento de los justos ${ }^{2}$}

La comunidad judía, tras el retomo a la tierra, desde el exilio en Babilonia, en el año 538, vivió diferentes crisis. Una de las últimas fue la producida por el triunfo del helenismo y, sobre todo, por la persecución violenta del rey Antloco IV (en torno a 175), quien quiso acabar con la cultura y la religión judías. Esto

2. Sobre el libro de la Sabiduría puede consultarse José Vîchez Líndez, Sabiduría. Comentario teológico y literario, Estella, 1990; José Ramón Busto, La justicia es inmorfal. Una lectura del libro de la Sabiduría de Salomón. Santander, 1992; Rafael de Sivatte, "El libro de la Sabiduría", La Sabiduría de Israel, ¿conformismo o liberación?. San Salvador, 1992, pp. 61-62; Daniel Doré, El libro de la Sabiduría de Salomon, Estella, 2003. 
produjo la reacción de muchos judíos y una guerra, en la cual muchos fieles y justos murieron, por defender su propio estilo de vida como creyentes en Yahveh. En esa época, los creyentes fueron llegando a la convicción de que la relación profunda con Dios no se puede romper, a pesar de la muerte. Llegaron a la fe de que no es posible que quienes han muerto mártires, defendiendo su fe y sus costumbres, mueran por siempre. Dios los resucitará.

Esta fe, sin embargo, tendrá su última prueba en el Antiguo Testamento, cuando la comunidad judía, independiente durante algún tiempo, después de la victoria macabea contra los helenistas, vuelva a caer en las opresiones internas de poderes de mala fe y en la dominación romana. La experiencia de que los inocentes y justos sufren a manos de los injustos y poderosos fue creciendo y obligó a la última reflexión sapiencial veterotestamentaria sobre esta problemática. Es lo que aparece en el libro de la Sabiduria, especialmente en sus primeros cinco capítulos.

Una de las primeras afirmaciones $(1,13-14)$ es que "Dios no hizo la muerte ni se alegra con la destrucción de los vivientes. El lo creó todo para que subsistiera: las criaturas del mundo son saludables... la tierra no es el reino de la muerte". Los injustos, en cambio, piensan que "la vida pasará como las nubes, sin dejar rastro... y el tiempo que vivimos es como el paso de una sombra" (2, 4-5). Y de ahr la conclusión de los injustos.

Disfrutemos de los bienes presentes... dejemos por todas partes huellas de nuestras orgfas... Oprimamos al pobre que es justo, no tengamos compasión de la viuda ni respetemos las canas llenas de años del anciano. Para nosotros es justo el que tiene la fuerza. La debilidad no lleva a ninguna parte $(2,6-11)$.

Y la razón profunda para poner trampas y oprimir al justo es que molesta y está en contra de lo que hacen los injustos, les echa en cara sus acciones, es una acusación viviente de sus ideas, declara que al final serán felices los justos y presume de tener a Dios como padre. Todo esto molesta a los injustos, quienes quieren poner a prueba al justo para ver si resiste, si Dios efectivamente se pone de su lado, si interviene a su favor (véase 2, 12-20).

Estos son sus pensamientos, pero se equivocan, porque no conocen cuáles son los designios de Dios, no saben que Dios ha hecho al ser humano a imagen de lo que él es, es decir, vida (véase 2, 21-24). La reflexión da un paso más y dice en 3, 1-9:

En cambio, la vida de los justos está en manos de Dios... Los insensatos pensaban que habían muerto; su tránsito les parecía una desgracia... pero ellos están en la paz... ellos tenían total esperanza en la inmortalidad... Dios les dará una felicidad inmensa... Los que confían en él comprenderán la verdad y los fieles a su amor permanecerán a su lado, pues él vendrá a visitar, con gracia y misericordia a sus elegidos. 
Lo contrario les pasará a los impíos e injustos que desprecian al justo (véase 3, 10-12). La Sabiduría toma una opción clara, que se contrapone a la opción de los injustos. Para ella, es más importante ser honrados, justos, fieles, que tener gran descendencia, ya que ésta no es auténtica descendencia si no va unida a la bondad (véase $3,13-4,6$ ).

Es más, según la Sabiduría (véase 4, 7-19), el valor de una persona no depende del tiempo largo o breve que viva. Lo que importa es la relación que haya tenido con Dios, la madurez a la que haya llegado. Esto hace que su recuerdo perdure, mientras que al injusto nunca jamás nadie lo recordará. En último término, los injustos

acudirán asustados... sus propios delitos los acusarán a la cara. Entonces, el justo aguantará firme y lleno de confianza frente a los que... despreciaron sus sufrimientos. Al verlo, quedarán sobrecogidos de espanto, desconcertados por la increible salvación... Y... con el espíritu angustiado, se dirán: "Éste es aquel de quien hace tiempo nos reíamos... Su vida nos parecía una locura, y su muerte, una deshonra. ¿Cómo es que ha sido incluido entre los hijos de Dios y comparte su herencia con los santos? Ciertamente, éramos nosotros los que estábamos equivocados... no hemos querido conocer el camino del Señor... ¿De qué nos ha servido nuestro orgullo?¿Qué nos han reportado las riquezas de que presumíamos? Todo aquello pasó como una sombra, como noticia que vuela; como nave... como pájaro... como flecha... sin dejar conocer su trayectoria. Lo mismo nosotros: apenas nacidos, desaparecemos; sin poder mostrar ningún signo de virtud... En efecto, la esperanza del impío... se disipa como el humo con el viento; pasa como el recuerdo del huésped de un solo día $(4,20-5,14)$.

La Sabiduría acaba diciendo:

Los justos, en cambio, viven para siempre... el Señor... cuida de ellos... con su diestra los protegerá... armará a la creación para vengarse de sus enemigos; vestirá la coraza de la justicia, se pondrá por casco la imparcialidad, empuñará como escudo invencible su santidad... el mundo entero luchará a su lado contra los insensatos... las malas acciones provocarán que caigan los tronos de los poderosos $(5,15-23)$.

En resumen, frente al problema de la persecución y la muerte del justo a manos de los injustos, la Sabiduría afirma que la autosuficiencia y el orgullo de los injustos y poderosos son algo vacío y falso, que no tiene fundamento alguno. Afirma también que las apariencias engañan, ya que la palabra definitiva no es la del injusto, sino la del justo; éste no muere, ya que la relación de Dios con él nunca se acaba. Afirma, finalmente, que se mantendrá siempre la esperanza de que el ser humano está hecho para la incorruptibilidad y la inmortalidad. 


\section{Conclusión}

Recojamos ahora las conclusiones sobre el tema de la fe del pueblo del Antiguo Testamento ante el sufrimiento. Recordemos muy brevemente lo que dijimos en al artículo anterior, sobre la postura de los profetas.

En Jeremías queda claro que Dios no está a favor del sufrimiento, pero reta al profeta a caminar en medio de él y a trabajar para eliminarlo. Dios le dará la fuerza para soportarlo y seguir adelante, en su misión.

En el caso de Habacuc, el profeta protesta a Dios, pues no entiende su manera de guiar la historia. En la línea de las respuestas que Dios daba a Jeremías, le exige a Habacuc mirar con ojos de fe la profundidad de la historia, pues sólo eso hará posible ver en ella su presencia oculta y misteriosa. Dios vuelve a pedir al profeta que siga firme en su inocencia y su justicia, las cuales se convertirán en la base y fundamento de su confianza y su vida.

En los cuatro cánticos del Siervo de Yahveh del Segundo Isaías, se da un avance progresivo, en la comprensión del sufrimiento, del siervo y de Yahve. En su conjunto, los cantos hablan de la fuerte intimidad del Siervo y Dios. Debido a esta quasi-identificación, Dios sufre, en último término, por medio de su Siervo y acompaña así a su pueblo sufriente para darle ánimo y ayudarlo a caminar, en medio del mal y del sufrimiento, siempre en el horizonte de eliminar a ambos.

Esto es lo que vimos en el artículo anterior. En el libro de Job, hay también una gran novedad. Aparece un Dios que no quiere, de ningún modo, el caos y la injusticia, que suponen el mal y el sufrimiento de los inocentes. Pero este Dios no usa su poder, destruyendo aquello o aquellos que provocan el sufrimiento, sino que cuenta con los seres humanos y su libertad para acabar con la injusticia y el sufrimiento, provocados por ella. Para ello, Dios intenta "seducir" al ser humano, mostrándole su preferencia y su estar a favor de los pobres y de los más desprotegidos, para que luche libremente contra la injusticia.

Este Dios llama a Job a salir de su propio mundo e ir al mundo de quienes sufren a su alrededor, pues Dios los quiere preferencialmente. Lo llama también a conseguir con la propia actitud y acción que los demás descubran y encuentren al Dios que no quiere el sufrimiento del inocente, sino que lo acompaña en todo su camino, hasta el final.

En resumen, lo que nos está diciendo Job es, en primer lugar, que desde la realidad del sufrimiento se "conoce" auténticamente a Dios, ya que no se trata de un Dios con quien se comercia, un Dios mágico, un Dios tapaagujeros, sino un Dios de la gratuidad y la libertad, el Dios metido en nuestra historia, encamado en la misma, interpelador, suscitador de personas y grupos que la transformen. Y en segundo lugar, que Dios está presente y es solidario, en las situaciones de sufrimiento y de dolor de los seres humanos, y de un modo especial, de 
los inocentes, animándolos a luchar contra el sufrimiento de los demás y contra el sufrimiento propio.

Finalmente, en el libro de la Sabiduría, frente al problema de la persecución y la muerte del justo a manos de los injustos, la Sabiduria afirma que la autosuficiencia y el orgullo de los injustos y poderosos son algo vacio y falso, que no tienen fundamento alguno. Afirma también que las apariencias engañan, ya que la palabra definitiva no es la del injusto, sino la del justo; éste no muere, ya que la relación de Dios con él nunca se acaba. Afirma, por último, que hay que mantener siempre la esperanza de que el ser humano está hecho para la incoruptibilidad y para la inmortalidad. El mal y el sufrimiento del justo, por tanto, están llamados a desaparecer.

El estudio de estos cinco testimonios veterotestamentarios ayuda a comprender mejor varias cosas. Ante todo, que el mal y el sufrimiento son realidades de nuestra existencia, muchas veces agudizadas por el mal uso que los opresores e injustos hacen de su libertad. Además, que Dios no soporta el mal y el sufrimiento que caen sobre el inocente y el justo, sino que desea que aquéllos desaparezcan. Que el ser humano está llamado a eliminar el mal y el sufrimiento de la humanidad, en la medida de sus limitadas posibilidades. Que, finalmente, Dios está al lado del inocente sufriente, que ha escuchado el llamado y se ha puesto a luchar hasta la muerte para que el mal y el sufrimiento sean eliminados de nuestro mundo. Nos ha llevado a comprender, en conclusión, que la última palabra de la historia no será el mal y el sufrimiento, sino el bien y la vida llena de dignidad. 